\title{
NO INSTA OU NO FACE? \\ Uma Análise Acerca da Presença da Marca Mary Jane nas Redes Sociais
}

Cristiano Max Pereira PINHEIRO ${ }^{1}$

Mauricio BARTH ${ }^{2}$

Luis Henrique RAUBER ${ }^{3}$

Juliana Michele WAGNER ${ }^{4}$

\begin{abstract}
${ }^{1}$ Doutorado em Comunicação Social (PUCRS); professor do Mestrado em Indústria Criativa (Universidade Feevale). E-mail: maxrs@ feevale.br.

${ }^{2}$ Mestrado em Indústria Criativa; professor no curso de Publicidade (Universidade Feevale). E-mail: mauricio@feevale.br.

${ }^{3}$ Mestrado em Inclusão Social e Acessibilidade; coordenador dos cursos de Fotografia e Design Gráfico (Universidade Feevale). E-mail: luishenrique @ feevale.br.

${ }^{4}$ Graduação em Publicidade e Propaganda (Universidade Feevale). E-mail: msjulianawagner@gmail.com.
\end{abstract}

Recebido em: 20/07/2015 - Aprovado em: 05/01/2016 - Disponibilizado em: 30/07/2016

\begin{abstract}
RESUMO
O presente trabalho tematiza sobre as redes sociais e apresenta como problema a falta de conteúdo exclusivo para o Instagram, considerando sua especificidade em relação às demais redes sociais. $\mathrm{O}$ artigo aprofunda duas hipóteses: a) as marcas não criam conteúdo exclusivo para o Instagram pois não possuem embasamento que comprove a eficácia desse método; b) as marcas não tempo, nem pessoas disponíveis, para a criação de conteúdos específicos para cada rede social. Os resultados obtidos corroboram com as hipóteses, confirmando o fato de que não há dados que justifiquem a criação de materiais exclusivos para as redes sociais, além da verificação de que as empresas não possuem pessoal disponível para o desenvolvimento deste trabalho.
\end{abstract}

Palavras-chave:Redes Sociais. Facebook. Instagram. Mary Jane.

\section{ABSTRACT}

This work thematizes on social networks and presents as a problem the lack of unique content to Instagram, considering its specificity in relation to other social networks. Article deepens two hypotheses: a) the marks do not create exclusive content for Instagram because they have no basis to prove the effectiveness of this method; b) marks no time or people available for creating specific content for each social network. The results corroborate the hypothesis, confirming the fact that there is no data supporting the creation of unique materials for social networks, as well as verification that the companies do not have staff available to develop this work.

Keywords:Social Networks. Facebook. Instagram. Mary Jane.

\section{INTRODUÇÃO}

A comunicação ganhou,com o advento da Internet, novas proporções. As redes sociais possibilitaram a criação de elos informais entre pessoas de diversos lugares do planeta e, ainda, viabilizaram o contato direto entre marcas e consumidores, além de proporcionar para as empresas a divulgação de seus produtos e serviços.
Apesar disso, trabalhar com redes sociais, criando conteúdos digitais para marcas, acompanhando a evolução das publicações e avaliando o retorno das mídias, não é uma tarefa simples. À vista disso, este trabalho tem como tema principal a geração de conteúdo da marca Mary Jane nas redes sociais Instagram e Facebook, uma vez que é perceptível a falta de material exclusivo e que leva em conta as 
peculiaridades de cada mídia social e, consequentemente, de cada público.

Investigaram-se,então, duas hipóteses para o problema levantado: (a) a primeira suposição é de que as marcas não criam conteúdos exclusivos para cada rede social por não possuírem princípios que justificam a eficácia dessa técnica, ou seja, para elas, não existem dados que comprovem o benefício de criar temas singulares para cada rede social. Dessa forma, as marcas escolhem o meio mais simplese acabam, apenas, replicando os conteúdos em ambas as redes sociais; (b) o segundo pressuposto é de que as empresas responsáveis pelas redes sociais das marcase, consequentemente, pela criação de conteúdo digital, não possuem tempo hábil, nem pessoas disponíveis para elaborar conteúdos específicos para cada rede. Dessa forma, mesmo sabendo que cada rede social possui suas individualidades, as marcas optam por desenvolver conteúdos maleáveis, que podem ser utilizados em ambas as mídias.

Com a finalidade de responder as hipóteses acima levantadas, o presente artigo foi desenvolvido com base em autores que fundamentam a análise, levando em consideração temas como Marketing Digitale Redes Sociais. A fim de aprofundar a análise com dados verídicos, o trabalho contou com amostra e coleta de dados, os quais foram colhidos no período de janeiro de 2015.

Sendo assim, a seção seguinte inicia as discussões.

\subsection{MARKETING DIGITAL}

O planejamento onlinedeve abranger toda a comunicação da empresa, pois a Internet acaba interferindo no Marketing mesmo quando as marcas ou produtos não estão na rede. Isso ocorre pois, na Internet, não é a empresa que controla o que está sendo dito sobre a marca; quem controla isso são os consumidores, que possuem voz ativa na rede para falar (tanto bem quanto mal) de um produtoe buscam, nesse diálogo, criar uma relação com as marcas.

Chleba (1999) sugere que, para se destacar em meio a concorrência e criar um bom relacionamento com o público, as empresas devem adotar sete forças. São elas:

1. Interatividade: É a troca de informações entre empresa e cliente, de forma rápida e eficaz, a fim de sanar dúvidas dos usuários, tanto quanto à utilização de um produto, quanto ao seu funcionamento. A interatividade na Internet "deve ser percebida como a possibilidade de o usuário, por meio dessa troca de dados, encontrar a informação ou facilidade que deseja" (p. 19).

2. Personalização: Ao contrário de outros meios como a TV, por exemplo, a Internet possibilita personalizar o atendimento a cada cliente, melhorando a prestação de serviços e o atendimento fornecido pela empresa, para isso, "os clientes precisam ser atendidos individualmente por serviços online ligados de 
autoatendimento aos bancos de dados das empresas" (p. 20).

3. Globalização: Quando uma empresa está na rede, ela está acessível a qualquer pessoa de qualquer lugar do mundo, possibilitando que usuários de diversas localidades conheçam a marca e, caso a mesma ofereça vendas online, realizem compras, mesmo em um local onde a empresa não possua loja física.

4. Integração: AInternet possibilita que as empresas se interliguem, a baixo custo, integrando sistemas e facilitando a vida dos usuários. Um exemplo disso é uma loja online, que está diretamente ligada a um sistema de pagamento online e ao site dos correios, pois o internauta consegue comprar na Internet, efetuar o pagamento e, ainda, acompanhar pela rede o status de envio da sua encomenda.

5. Aproximação: A Internet aproxima consumidores e produtores. Isto é bom para a empresa, que recebe um feedback dos seus produtos mais facilmente, e para o consumidor, que tem um contato direto com a empresa.

6. Convergência: A empresa pode estar presente em diferentes mídias, transmitindo a mesma mensagem, porém, de maneiras diferentes, ajustadas a cada mídia.

7. Democratização da informação: AInternet é uma mídia barata em relação às demaise oferece disponibilidade de estar em contato com o mundo todo em poucos segundos.
Para Salomon (2013), existem empresas que ainda não sabem como se portar na Internet, permanecendo "perdidas" na rede, sem um direcionamento adequado. Segundo Boyd (2008), para uma empresa estar na Internet de forma eficiente não basta criar um site ou anunciar em um banner; é necessário alinhar a comunicação, sem investir, apenas, em recursos isolados. É necessário entender a Internet e conhecer seu público, para, aí sim, planejar de maneira eficiente.

\subsection{REDES SOCIAIS}

A ascensão da web 2.0, deixando de ser um meio de informação para se tornar um meio de colaboração, fez com que as pessoas se tornassem ativas na rede, produzindo conteúdos, colaborando com ideias nos materiais assistidos, trocando informações e, de forma geral, se comunicando. Os blogs foram uma das primeiras ferramentas que possibilitaram essa interação por parte dos usuários, abrindo espaço para outros meios, como, por exemplo, as redes sociais (BOYD, 2008).

As pessoas sentem a necessidade de se comunicar, criando elos com aqueles que fazem parte do seu círculo de amizade, se informando sobre o que está acontecendo na vida das outras pessoas, comentando e compartilhando o conteúdo gerado pelos seus contatos. De acordo com Ramalho (2010, p. 11): “O que entendemos hoje como mídias sociais nada 
mais é do que a forma moderna de se praticar uma das principais necessidades do ser humano: a socialização". Sendo assim, as redes sociais são como uma extensão do mundo real para o mundo virtual, onde todos ficam sabendo dos acontecimentos de seus contatos mesmo estando longe (BOYD; ELLISON, 2008).

Assim como na comunicação offline, o diálogo no mundo virtual também pode ser interpessoal ou massivo. De acordo com Recuero (2009, p. 24): "Uma rede social é definida como um conjunto de dois elementos: atores (pessoas, instituições ou grupos; os nós da rede) e suas conexões (interações ou laços sociais)".Em uma rede social, as pessoas criam ligações com os demais usuários da rede como no mundo real, instituindo laços sociais. É como um grande grupo de amigos reunidos que possuem diferentes níveis de relacionamento entre si, mas estão todos interligados e partilhando informações a respeito de sua vida. Em certos momentos, a comunicação pode ser interpessoal, com duas pessoas conversando em chats privados; em outros momentos, um indivíduo pode publicar uma frase ou um pensamento em modo público, fazendo com que a conversa seja de um para todos (MANGOLD; FAULDS, 2009).

As representações dos atores sociais citadas por Recuero, nada mais são do que as formas como os indivíduos se apresentam na rede. Por se tratar de uma conversa virtual, onde as pessoas podem ou não se conhecer pessoalmente, os atores podem ser representados de diversas maneiras: um perfil de Facebook, um blog, um Twitter, um Instagram ou, ainda, um vídeo-blogger. Ainda, de acordo com Recuero (2009), essas ferramentas de representação dos atores não são exatamente os indivíduos, mas, sim, lugares onde estes se comunicam e interagem, transmitindo sua personalidade e demonstrando sua individualidade.

\section{METODOLOGIA}

Com o intuito de analisar a comunicação digital da marcaMary Jane, utilizou-se a análise de conteúdo, que, segundo Bardin (1977, p. 27) “é um conjunto de técnicas de análise das comunicações", ou seja, a mesma trata de diferentes práticas que buscam encontrar respostas a respeito dos símbolos, linguagem e imagens utilizadas em determinada comunicação, de forma objetiva e clara.

Um dos métodos a serem utilizados para a análise de conteúdo é o método de definição de categorias. Segundo Bardin (1977, p. 32), esse procedimento é uma “[...] espécie de gavetas ou rubricas significativas que permitem a classificação dos elementos de significação constitutivos da mensagem".Sendo assim, houve a possibilidade de dividir as publicações coletadas em "Postagens Exclusivas", "Postagens Replicadas na mesma data", "Postagens Replicadas primeiro no Instagram" 
e "Postagens Replicadas primeiro no Facebook".

A organização do conteúdo é o primeiro passo, fase que é chamada de pré-análise. "Esta fase possui três missões: a escolha dos documentos a serem submetidos à análise, a formulação das hipóteses e dos objetivos e a elaboração de indicadores que fundamentem a interpretação final”' (BARDIN, 1977, p. 89). No caso destetrabalho, os documentos escolhidos para análise foram as postagens de imagens no Facebook e no Instagram, a fim de responder os questionamentos quanto a criação de conteúdo exclusivo. O objetivo do trabalho é descobrir, analisando o conteúdo publicado, se o mesmo foi criado exclusivamente para o Instagram e possui eficácia melhor que aquele replicado do Facebook, além de verificar se as empresas possuem profissionais disponíveis para a tarefa.

De acordo com Bardin (1977, p. 95), a exploração do material coletado, que constitui a segunda parte da análise, é a etapa em que a coleta é ordenada por suas semelhanças entre si, para, assim, obterem-se as características que serão analisadas posteriormente. $\mathrm{O}$ tratamento do material é uma das principais fases da análise de conteúdo, pois é a parte em que os documentos são codificados. "A codificação é o processo pelo qual os dados brutos são transformados sistematicamente $\mathrm{e}$ agregados em unidades, os quais permitem uma descrição exata das características pertinentes ao conteúdo" (BARDIN, 1977, p. 97). Só depois de codificados os dados é que será obtida uma noção geral dos documentos agrupados, para, assim, a análise adquirir uma estrutura a ser verificada.

A pesquisa apresenta uma análise quantitativa, pois, tem como base números estatísticos, utilizando-se de dados coletados nos perfis das redes sociais da marca a ser analisada. "A análise quantitativa funda-se na frequência de aparição de certos elementos da mensagem" (BARDIN, 1977, p. 107). A amostra a ser coletada corresponde ao mês de janeiro de 2015, período em que a maioria do público está de férias, dispondo, portanto,de mais tempo livre para atuação nas redes sociais e Internet (KAPLAN; HAENLEIN, 2010). Foram analisadas as imagens publicadas no Facebook e Instagram da marca, salvando os dados em arquivos no formato PDF com a imagem do post publicado, com a quantidade de curtidas, além de uma legenda com a quantidade de comentários de cada postagem, sendo um arquivo para cada rede social da marca.

\section{ANÁLISES}

A marca Mary Jane publicou no mês de janeiro de 2015, 59 imagens no Instagram da marca, contabilizando um total de 58.709 curtidas nas publicações e 898 comentários. O perfil da marca na rede social conta com 32.600 seguidores $^{1}$, que juntos realizaram 59.607 
interações com a marca no período de 31 dias. Conforme abordado naseção anterior, a geração digital preza pela colaboração, mantendo contato com as marcas que segue nos perfis das redes sociais (TAPSCOTT, 2010). Os números apresentados indicam um bom número de curtidas e comentários nas publicações.

As publicações analisadas foram divididas em "Imagens Exclusivas para o Instagram", que contabilizou 12 postagens, e "Imagens replicadas no Facebook", no total de 47 publicações. Abaixo, encontra-se, em forma de gráfico, o resultado dessa classificação.

\section{Gráfico 1 - Publicações no Instagram - Janeiro}

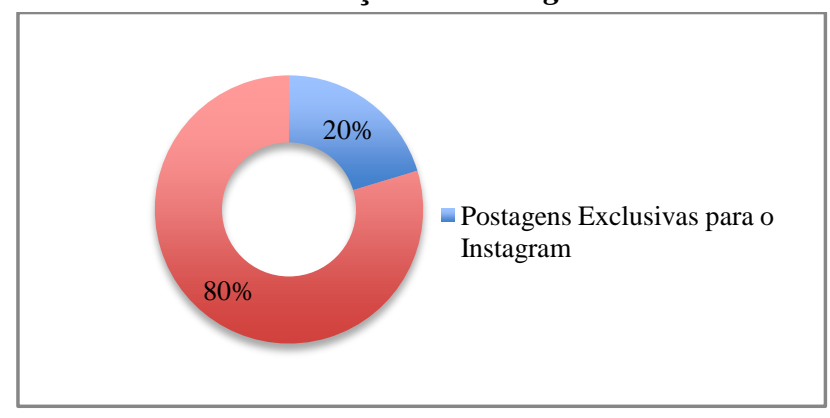

Fonte: Elaborado pelos autores

No canal da marca no Facebook, que possui 723 mil curtidores, a empresa publicou na sua página 51 imagens no período de janeiro de 2015, gerando 67.103 interações entre os fãs; destas, se contabilizam 65.859 curtidas em publicações e 1244 comentários.

A quantidade de fãs na página da marca na rede, em comparação com a quantidade de seguidores do Instagram, é alta, porém, se deve, principalmente, ao fato de que a geração digital possui uma relação natural com a tecnologia (TAPSCOTT, 2010), permanecendo online praticamente $24 \mathrm{~h}$ por dia, tanto em casa, como no trabalho ou em ambiente escolar. E essa conectividade, aliada às características dos jovens em querer velocidade na informação e no entretenimento, se tornou um fator positivo para as marcas que possuem página no Facebook, pois o canal possibilita diversas customizações, além do fato de ser acessado tanto de dispositivos mobiles quando de desktops.

O gráfico 2 mostra o percentual de publicações por categoria, dividido em "Imagens exclusivas para o Facebook", que somam 4 publicações,e "Imagens replicadas no Instagram", no total de 47 postagens.

Gráfico 2 - Publicações no Facebook - Janeiro

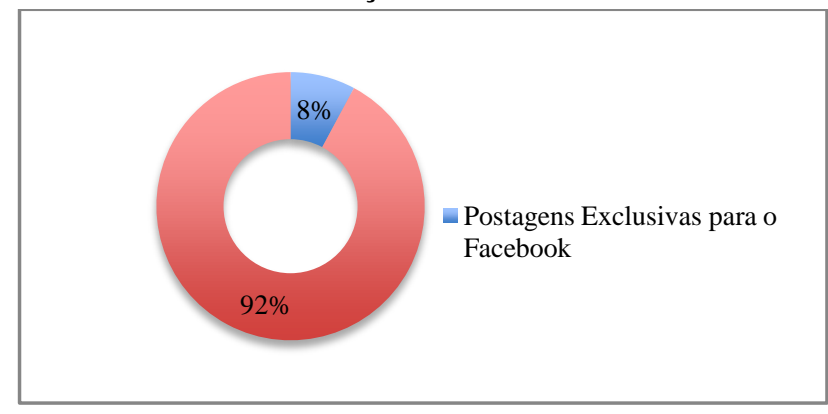

Fonte: Elaborado pelos autores

Ao analisar as publicações do Instagram da marca, pode-se observar que no período de janeiro de 2015, a média de curtidas por imagem publicada foi de 995 curtidas, o que representa 3,05\% dos seguidores da marca na rede social. A interação por comentários possui uma média de 15 comentários por imagem no período explorado, correspondendo a $0,04 \%$ dos seguidores. 
Na fanpage da marca no Facebook, nota-se que no mês de análise houve uma média de 1291 curtidas por imagem publicada, o que corresponde a $0,17 \%$ dos 723 mil fãs no canal. No mesmo intervalo, a média de comentários por publicação de imagens foi de 1244, representando $0,003 \%$ dos curtidores da página na rede.É provável que um dos fatores para a baixa representatividade de curtidas $\mathrm{e}$ comentários em ambos os canais seja a falta de entretenimento no conteúdo gerado. De acordo com Boyd e Ellison (2008) e Tapscott (2010), a geração digital quer se engajar com a marca, se entreter, personalizar e colaborar no que é consumido.

\section{Gráfico 3 - Percentual de interatividade média -} Janeiro

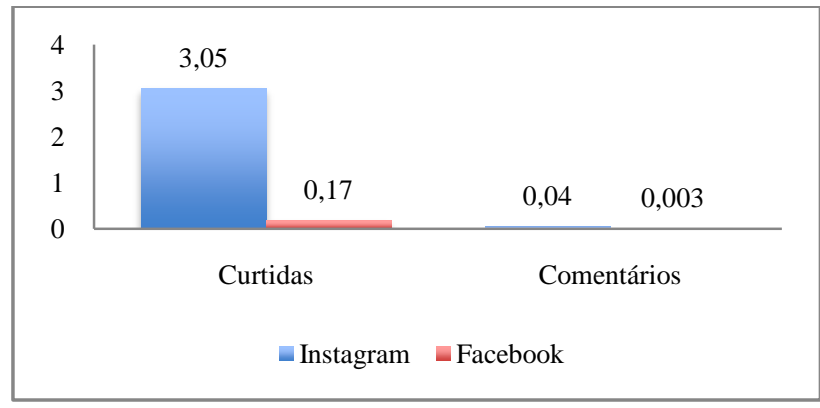

Fonte: Elaborado pelos autores

Ao analisar somente as publicações do Instagram da Mary Jane, 12 imagens são exclusivas para esta rede social, com um total de 11.684 curtidas e 173 comentários, enquanto que as imagens replicadas no Facebookda marca somam 47 publicações, 47.025 curtidas e 725 comentários. O gráfico abaixo apresenta o percentual de curtidas e comentários por categoriado montante do período de janeiro, em que foram contabilizados 58.709 curtidas e 898 comentários no Instagram da marca.

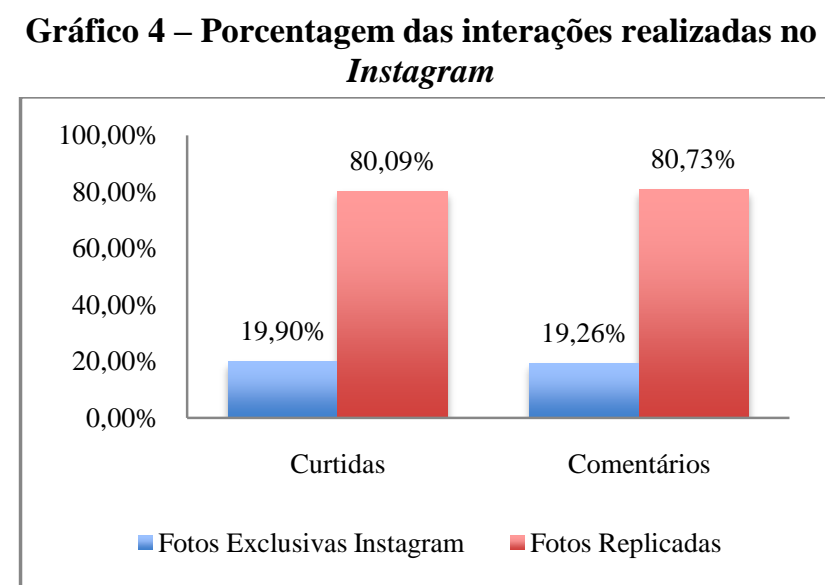

Fonte: Elaborado pelos autores

Analisando o gráfico, nota-se que o percentual de curtidas e comentários acompanha a porcentagem do tipo de publicações, não apresentando grandes variações, ou seja, ao mesmo tempo que as fotos exclusivas para o Instagram representam $20 \%$ do total das publicações, o número de curtidas e comentários acompanha esse dado, com variação inferior a $1 \%$.

Porém, se avaliarmos as publicações por tema, é possível perceber variações de percentual tanto de curtidas quanto de comentários. As 59 publicações foram divididas em 8 temáticas, com base nas imagens publicadas: Datas Comemorativas, que são as publicações fazendo alusão à alguma data do período, com 2 postagens; prévia de coleção, que possui 8 imagens no mês trazendo pequenas partes da coleção 2015 que ainda não havia sido lançada; dicas e assuntos gerais, que somam 9 postagens com dicas de moda, cabelo 
e outros assuntos de interesse do público; dica de look com produto, com combinações de roupas e acessórios ao produto, no total de 8 imagens; interação com usuários ou regrams, que são imagens postadas ou enviadas por usuários na rede e replicadas no canal da marca, que contabilizaram no período 4 publicações; frases e pensamentos, com 5 postagens; e produtos, que são fotos apenas do produto, com ou sem ambientação, no total de 23 publicações. O gráfico a seguir apresenta a divisão por temas com os percentuais de cada item.

\section{Gráfico 5 - Temas das imagens - Instagram Janeiro}

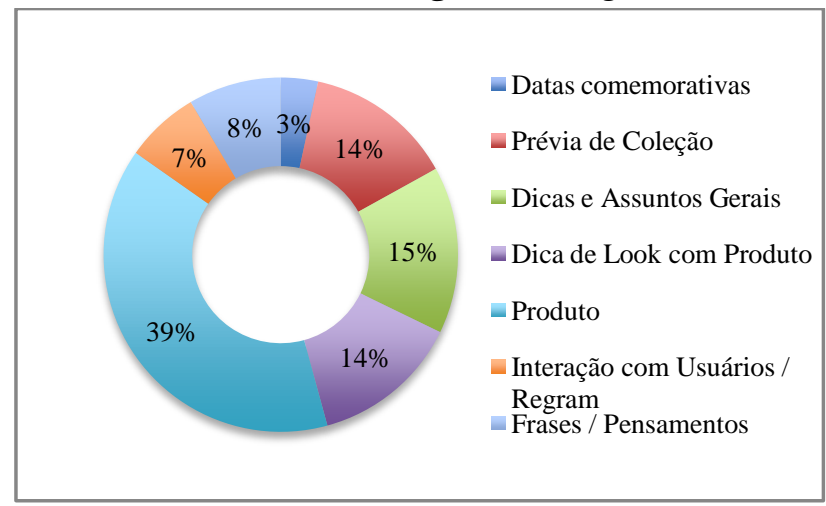

Fonte: Elaborado pelos autores

Ao analisar as postagens por tema, é possível notar que o percentual se altera quando observado o número de curtidas. Vale ressaltar, aqui, que os temas que se destacam no percentual de curtidas são: "Produto" pelo número maior de curtidas e "Dicas e Assuntos Gerais" pela queda de representatividade no total. Uma das prováveis razões para esses acontecimentos é que, ao publicar os produtos da marca, aempresa é coerente, fazendo uma publicidade que funciona com o público-alvo, indo ao encontro do que Boyd (2008) e Boyd e Ellison (2008) defendem como publicidade eficaz.

Ao mesmo tempo em que as postagens de produtos são bem sucedidas, o contrário ocorre com as dicas e assuntos gerais publicados. A resposta plausível para essa queda de representatividade pode ser encontrada nas características da geração digital que, segundo Tapscott (2010) e Salomon (2013), prezam pela liberdade e agilidade, ou seja, é provável que as dicas publicadas pela marca já tenham sido visualizadas pelo público em outro meio e os seguidores optam por curtir a página no Instagram exatamente para ver o produto, sua usabilidade e saber mais sobre a marca e, não, para obter dicas de assuntos aleatórios.

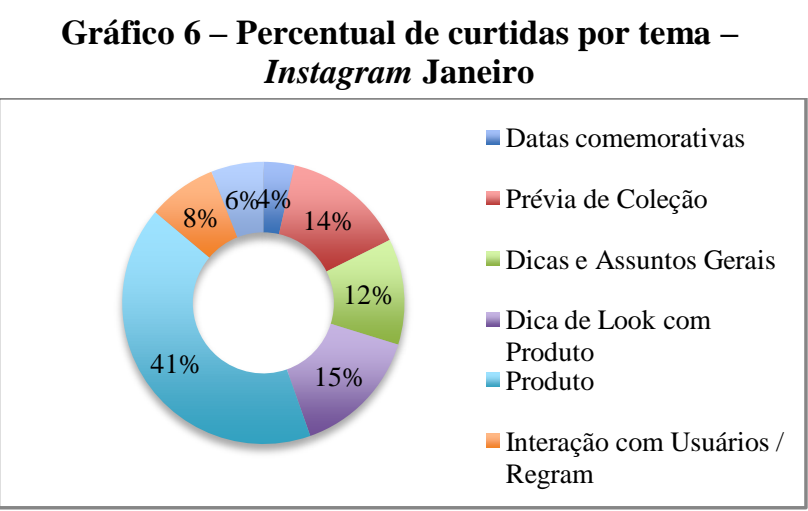

Fonte: Elaborado pelos autores

A representatividade do tema "Produtos" fica ainda maior quando analisado o número de comentários nas publicações. Isso se deve principalmente ao fato de muitas pessoas questionarem nas postagens o local da venda, elogiarem o produto ou realizarem críticas. Essa interação entre marca e público é o que 
Steinberg(2012) explica como Web 2.0, em que as pessoas querem participar, comentar e obter retornos; e é, também, o dinamismo que Tapscott (2010) apresenta na geração digital, em que a rapidez e a colaboração são qualidades valorizadas pelo público. Ao mesmo tempo, quando a marca se utiliza do canal para promover o diálogo com o público, ela cria a aproximação e interatividade que Chleba (1999) defende como diferenciais do Marketing Digital, trazendo retornos positivos para a empresa.

\section{Gráfico 7 - Percentual de Comentários por tema - Instagram Janeiro}

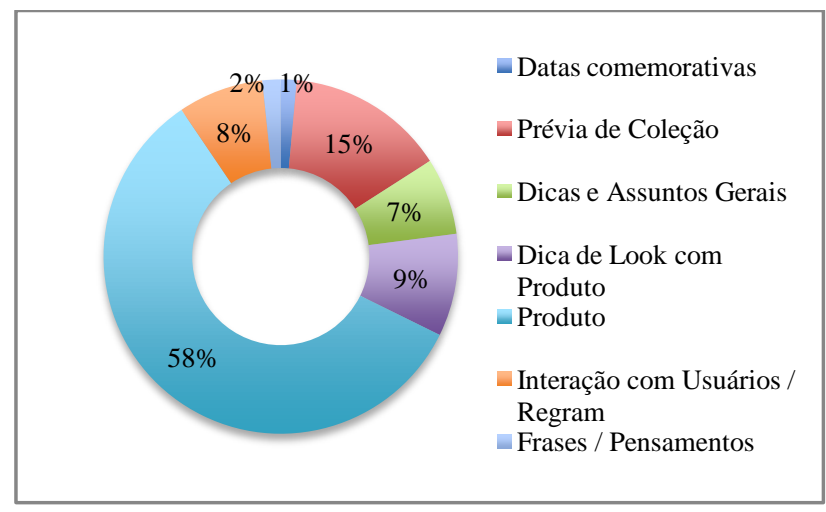

Fonte: Elaborado pelos autores

Quanto às publicações do Facebook, a marca publicou, em janeiro de 2015, 47 imagens replicadas do Instagram, que somaram 61.148 curtidas nas postagens e 1.152 comentários. Com as 4 imagens que foram publicadas, exclusivamente, no Facebook, a marca adquiriu 4.711 curtidas e 92 comentários nas publicações. A seguir, é possível observar o gráfico com a representação dos dados em percentuais de curtidas e comentários.
Gráfico 8 - Porcentagem das interações realizadas no Facebook

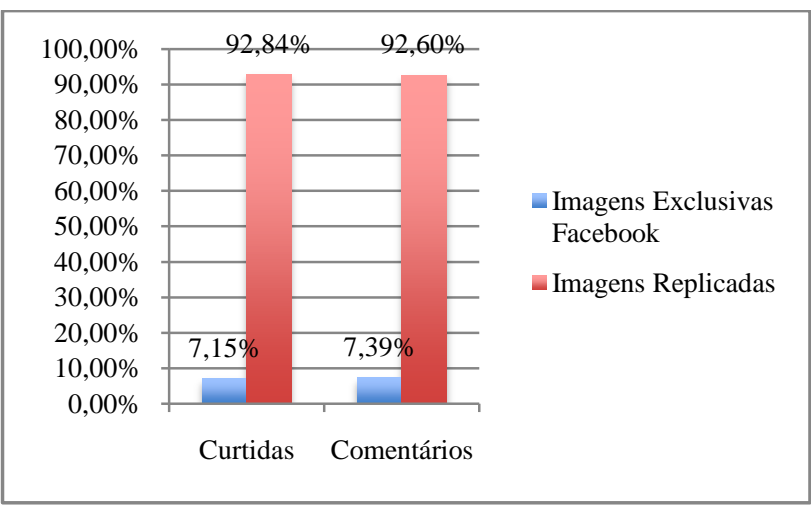

Fonte: Elaborado pelos autores

Ao calcular a representação das curtidas das publicações em comparação ao número de seguidores da marca nos canais, o Instagram se mostra com um número maior de seguidores engajados com a marca, com um total de $2,98 \%$ de curtidores nas postagens exclusivas para o canal, contra $0,16 \%$ do Facebook; enquanto que, nas imagens replicadas, possui 3,06\% de curtidores contra $0,17 \%$ do Facebook. O gráfico a seguir mostra a comparação.

\section{Gráfico 9 - Comparação da Representatividade de} Curtidas em Publicações

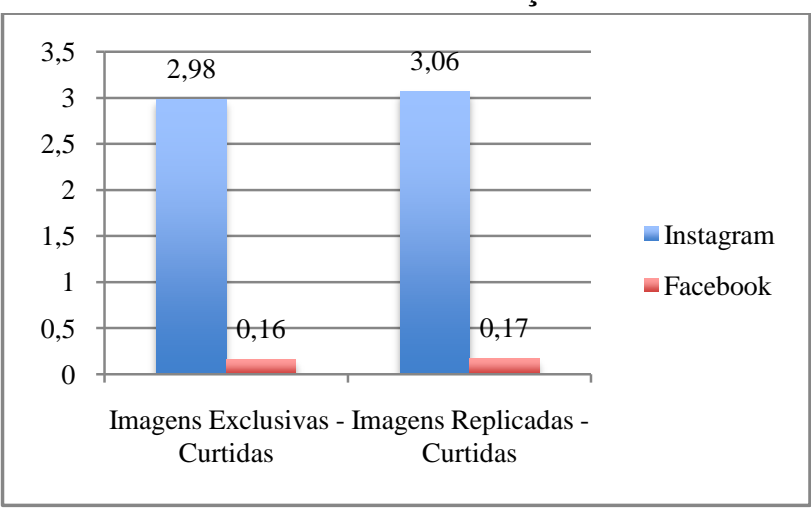

Fonte: Elaborado pelos autores

Um item a ser destacado na análise é que, de acordo com Chleba (1999), uma das forças do Marketing Digital é a Convergência, ou então, a possibilidade de transmitir a mesma 
mensagem, em canais diferentes, com alterações de conteúdo. Porém, nas publicações analisadas, a única alteração (quando essa ocorria) era a legenda da imagem publicada, inserindo ou retirando hashtags. É possível perceber, também, que não há uma diferença na temática do conteúdo exclusivo para as redes daqueles que são replicados, o que caracteriza a falta de convergência e personalização, aspectos apresentados por Chleba como diferenciais.

Quando analisada a mesma representatividade para os comentários das publicações, a diferença não é tão perceptível, mas, ainda assim, o Instagram se mantém à frente do Facebook, com um total de 0,04\% de comentários nas postagens exclusivas para o canal, contra $0,003 \%$ do Facebook; números que se repetem nas publicações replicadas. A seguir, o gráfico comparativo.

\section{Gráfico 10 - Comparação da Representatividade de} Comentários em Publicações

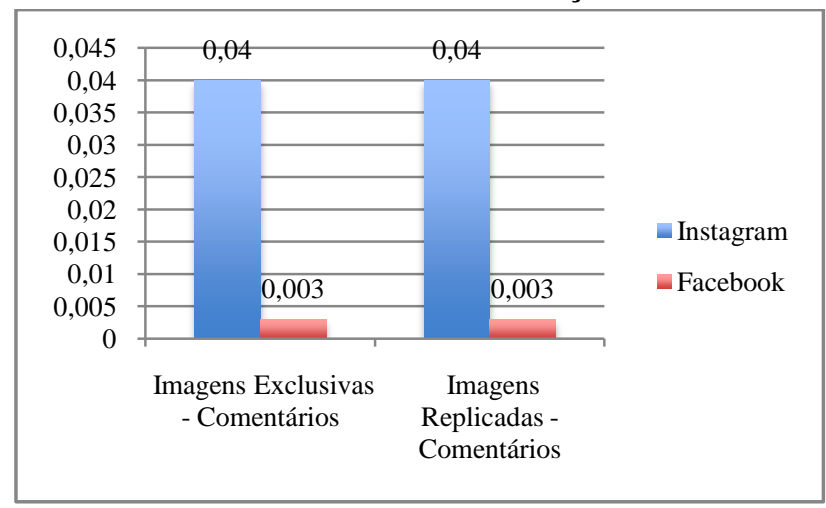

Fonte: Elaborado pelos autores

Observando todas as publicações das duas redes sociais analisadas no período de janeiro, pode-se perceber que não há uma grande diferença de interação das postagens que são exclusivas para uma rede social, daquelas que são replicadas nas mídias. O gráfico abaixo demonstra a representatividade média das interações no Facebook e Instagram.

Gráfico 11 - Representatividade das publicações

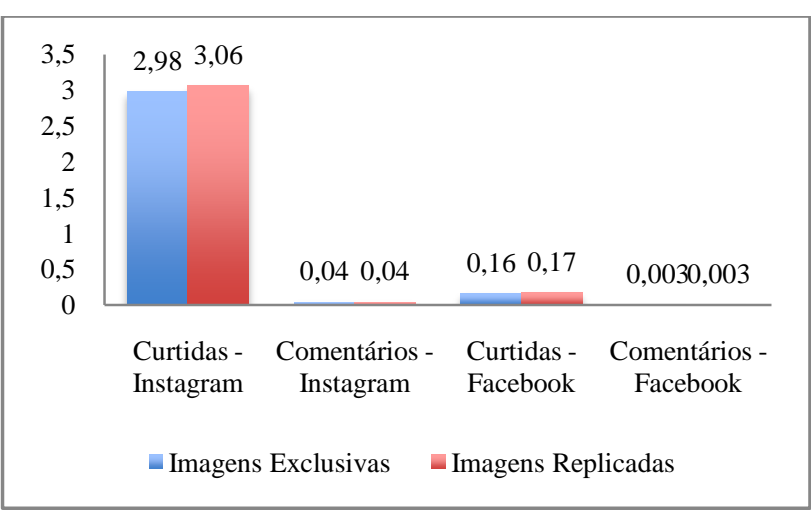

Fonte: Elaborado pelos autores

Para verificar se há diferenças nas interações entreposts exclusivos e replicados, foram analisadas, também, as postagens por tema do Instagram, a fim de identificar as diferentes interações. O gráfico a seguir mostra o percentual de publicações exclusivas e publicações replicadas, a fim de se obter uma base de análise.

Gráfico 12 - Percentual de publicações por tipo - exclusivas e replicadas

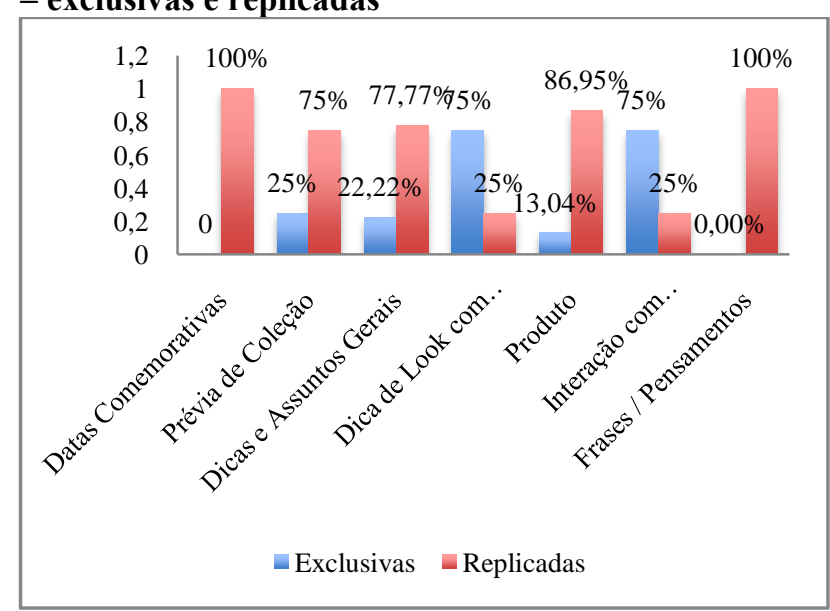

Fonte: Elaborado pelos autores 
Os números mostram que não há uma diferença representativa de curtidas entre as postagens que são exclusivas para aquelas que são replicadas. Porém, um dos itens se destaca por não seguir a mesma linha dos demais temas. Das publicações com o tema "Dica de Look com Produto", 75\% eram imagens exclusivas para o Instagram, contra $25 \%$ de replicadas; porém, ao analisar o percentual de curtidas, os números sofrem uma grande alteração, contando com apenas $28 \%$ das curtidas para as postagens exclusivas, enquanto que as imagens replicadas na rede obtiveram $72 \%$ das curtidas desse segmento. A seguir, pode-se observar o gráfico com os dados das curtidas por tipo de publicação.

Gráfico 13 - Percentual de curtidas por tipo de publicação

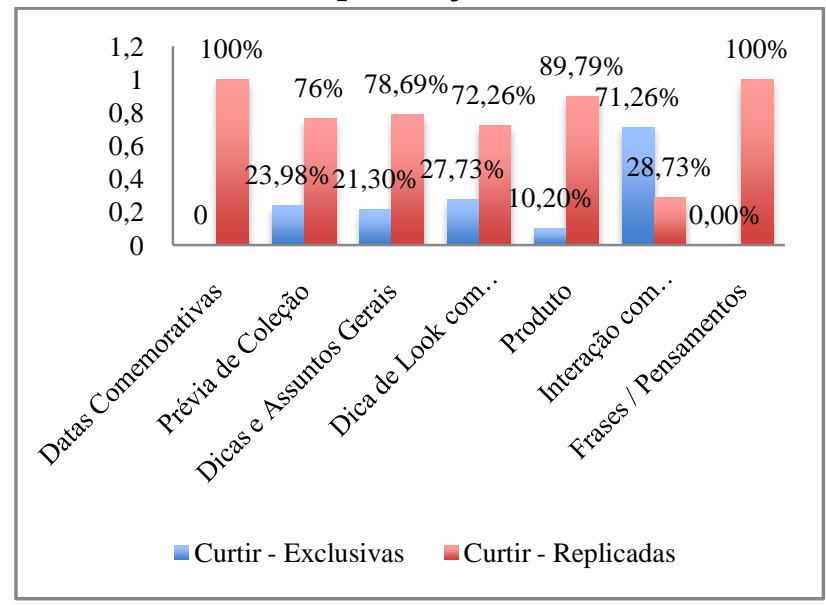

Fonte: Elaborado pelos autores

Os números de comentários também foram analisados, verificando o percentual de comentários nos posts exclusivos e dos posts replicados, separados por tipo de publicação. Ao analisar o gráfico a seguir, é possível perceber que o percentual de comentários se altera mais do que o de curtidas, em relação à porcentagem de publicações exclusivas e replicadas. Uma das temáticas que mais chama atenção é a "Prévia de Coleção", em que as postagens exclusivas representavam $25 \%$ das publicações e em número de comentários os posts exclusivos ganham destaque, com $42 \%$ das interações. Já o tema "Dicas e Assuntos Gerais" segue no caminho oposto, com uma queda acentuada de percentual de comentários nas postagens exclusivas.

\section{Gráfico 14 - Percentual de comentários por tipo de} publicação

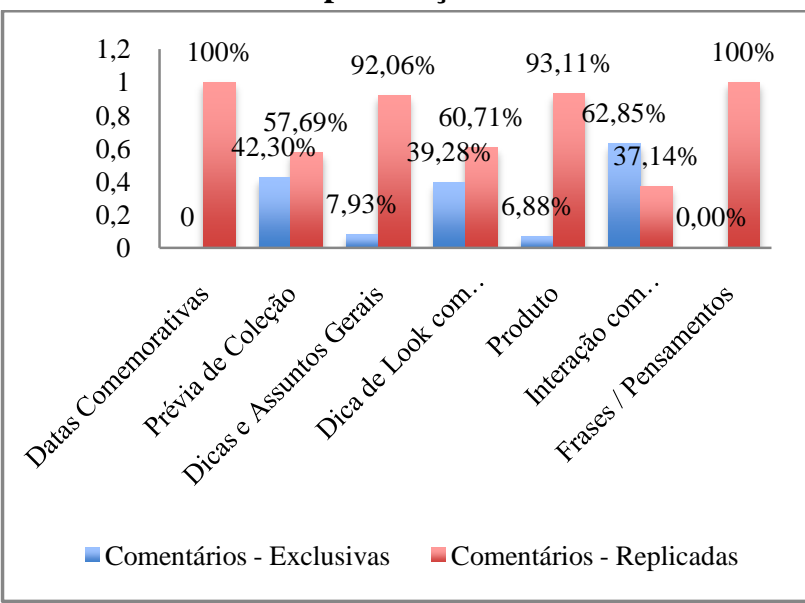

Fonte: Elaborado pelos autores

\section{CONSIDERAÇÕES FINAIS}

Os dados levantados na análise da marca Mary Janemostram alguns pontos importantes que devem ser levados em consideração: a marca possui um número de fãs no Facebookbem maior do que o número de seguidores do Instagram, porém, os usuários da segunda rede social possuem maior interação com a marca. Um dos fatores que pode ser responsável por esse dado é o fato do Facebook 
possuir uma política de patrocínio de publicações, enquanto que o Instagram não conta com essa ferramenta e, portanto, atinge todos os seguidores da marca no canal, ao contrário do Facebook que atinge apenas uma parcela dos fãs da página.

Outro ponto interessante é que as publicações de produtos da marca possuem maior interação do que postagens com outras temáticas, em que a marca tenta se aproximar dos seguidores com assuntos de interesse do público. Possivelmente, o fato ocorre porque o público segue a marca nas redes sociais para manter-se atualizado em relação aos produtos e lançamentos e, então, dá mais atenção a isso do que para as demais publicações, gerando, assim, uma maior interação nesse tema.

Por fim, percebe-se que não há uma diferença notável entre as publicações exclusivas daquelas que são replicadas em ambas as redes sociais e, embora não seja possível saber se o público que curte a publicação no Instagram é o mesmo que curte o post no Facebook, é interessante perceber que as postagens replicadas nas redes sociais possuem, algumas vezes, mais engajamento do público do que as exclusivas para o Instagram ou Facebook.

\section{REFERÊNCIAS}

BARDIN, L. Análise de conteúdo. 3. ed.

Lisboa, Portugal: Edições 70, 2004.
BOYD, D. M. Facebook's Privacy Trainwreck: Exposure, Invasion, and Social Convergence. Convergence: The International Journal of Research into New Media Technologies, London, v. 14, Issue1, 2008, p. 13-20.

BOYD, D. M.; ELLISON, N. B. Social Network Sites: Definition, History and Scholarship. Journalof Computer-Mediated Communication, v. 13, 2008, p. 210-230.

CHLEBA, M. Marketing Digital: novas tecnologias e novos modelos de negócios. São Paulo, SP: Futura, 1999.

KAPLAN, A. M.; HAENLEIN, M. Users of the world, unite! The challenges and opportunities of social media.Business Horizons, v. 53, n. 1, 2010, p. 59-68.

MANGOLD, G.; FAULDS, D. J. Social media: The new hybrid element of the promotion mix. Business Horizons, v. 52, n. 4, 2009, p. 357365.

RAMALHO, J.A. Mídias Sociais na prática. São Paulo: Elsevier, 2010.

RECUERO, R. Redes Sociais na Internet. Porto Alegre: Sulina, 2009.

SALOMON, D. Moving on from Facebook: Using Instagram to connect with undergraduates and engage in teaching and learning. College and Research Libraries News, v. 74, n. 8, 2013, p. 408-412.

STEINBERG, A. Exploring Web 2.0 political engagement: Is new technology reducing the biases of political participation?Electoral Studies, n. 39, 2015, p. 102-116.

TAPSCOTT, D. A Hora da Geração Digital: Como os jovens que cresceram usando a Internet estão mudando tudo, das empresas aos governos. Rio de Janeiro: AgirNegócios, 2010. 